\title{
DESAIN DAN SIMULASI TEGANGAN PADA MESIN CNC LASER CUTTING UNTUK PRODUK BERBAHAN ACRILIC
}

\author{
Mohamad Syaifullah \\ Program Studi Teknik Mesin \\ Universitas Muria Kudus \\ Email: syaifulla@gmail.com \\ Masruki Kabib \\ Program Studi Teknik Mesin \\ Universitas Muria Kudus \\ Email: masruki.kabib@umk.ac.id \\ Akhmad Zidni Hudaya \\ Program Studi Teknik Mesin \\ Universitas Muria Kudus \\ Email: $\underline{\text { Akhmad.zidni@umk.ac.id }}$
}

\begin{abstract}
ABSTRAK
Penelitian ini bertujuan mendesain mesin CNC Laser Cutting bersifat portable, alat ini menggunakan laser sebagai alat potong untuk mengerjakan benda kerja, dengan ukuran laser berdiameter 0,02 $\mathrm{mm}$, Metode penelitian yang digunakan untuk tahap perancangan yaitu melakukan studi literatur lalu menganalisa kebutuhan pembuatan mesin, memilih dan membandingkan beberapa alternatif desain, melakukan pemilihan konsep, perancangan modul laser serta, perancangan sistem gerak 3 axis, perancangan daya motor serta mensimulasikan frame dengan menggunakan metode elemen hingga. Hasil penelitian ini memperoleh skematik sistem kontrol mesin CNC Laser, menghasilkan prototipe mesin CNC Laser, dan nilai parameter dari data-data hasil uji kinerja mesin CNC Laser dengan microcontroller CNC 3 aksis berbasis Atmega328 Arduino nano dengan modul laser 5,5 Watt dengan kapasitas maksimal bidang kerja 200x100x10 mm. Hasil simulasi tegangan von mesis stress sebesar $0,07658 \mathrm{MPa}$.
\end{abstract}

Kata kunci: mesin cnc, laser cutting, akrilik

\begin{abstract}
The objective of research is to design a portable CNC Laser Cutting machine, this tool uses a laser as a cutting tool to work on a workpiece, with a laser size of $0.02 \mathrm{~mm}$ in diameter, and comparing several design alternatives, making concept selection, designing laser modules as well, designing 3 axis motion systems, designing motor power and simulating frames using the finite element method. The results of this research was obtained a schematic of a CNC Laser machine control system, producing a prototype CNC Laser machine and the parameter value of the performance test data of a CNC Laser machine with a 3-axis CNC microcontroller based on Atmega328 Arduino nano with a 5.5 Watt laser module with a maximum work area capacity of $200 \times 100 \times 10 \mathrm{~mm}$. The simulation results of the stress von misses stress is $0.07658 \mathrm{MPa}$.
\end{abstract}


Key words: CNC machine, laser cutting, acrilyc.

\section{PENDAHULUAN}

Kemajuan ilmu pengetahuan dan teknologi di industri saat ini berkembang dengan cepat terutama di bidang otomasih industri. Perkembangan ini dapat dilihat dengan jelas di perindustrian Indonesia, mulai dari yang awalnya banyak pekerjaan menggunakan tenaga manusia, kemudian berkembang berubah menggunakan mesin dan pekerjanya beralih menjadi operator. Tujuan mengotomasi sebuah proses adalah untuk menciptakan kualitas produk yang tinggi, mengurangi biaya produksi, dan mengurangi waktu produksi dalam suatu proses produksi [1].

Mesin CNC memiliki dua atau lebih arah gerakan yang disebut dengan sumbu axis. Gerakan pada axis antara lain linear yang merupakan garis lurus atau gerakan circular yang merupakan gerakan melingkar. Pada umumnya sumbu yang terdapat pada mesin CNC adalah X, Y, dan Z. Salah satu spesifikasi yang dapat dapat memperlihatkan kerja yang kompleks dari mesin $\mathrm{CNC}$ adalah berupa banyak axis yang dimilikinya serta kombinasi gerakan pada setiap axisnya [2].

Prinsip kerja pemotongan laser adalah mengarahkan sinar laser daya tinggi ke material yang akan dipotong melalui computer. Teknologi pemotongan laser perusahaan dapat memotong bentuk yang sulit diproses pada mesin milling CNC. Hasil yang didapat cukup akurat karena memiliki tingkat akurasi $0,001 \mathrm{~mm}$. Frekuensi operasi dioda pemotongan laser itu sendiri dalam spektrum yang terlihat adalah sekitar $1014 \mathrm{~Hz}-15 \mathrm{~Hz}$, atau ratusan ribu kali frekuensi gelombang mikro. Cahaya yang dihasilkan digunakan untuk memotong berbagai bahan, seperti akrilik, plat besi [3].

Beberapa mesin yang dikembangkan oleh peneliti sebelumnya, salah satunya adalah mesin pemotongan laser G-Weike LC6090 yang digunakan untuk melakukan proses pemotongan dan pengukiran. Menurut informasi yang diberikan oleh pemasok, mesin tersebut mampu mengolah berbagai bahan, seperti akrilik, polikarbonat, kayu MDF, kayu lapis, kulit, PCB, dan kertas. Kekurangan dari mesin ini adalah tidak menggunakan sumbu 3 sumbu, melainkan hanya 2 sumbu [4].

Saat ini di pasaran banyak tersedia bermacam macam alat potong mekanis yang sudah otomasi, termasuk diantaranya yang berbasis Computer Numerically Controlled (CNC).

CNC (Computer Numerical Control) adalah suatu mesin yang dikendalikan secara numerik oleh komputer atau mikrokontroler. CNC diciptakan karena pengoperasian mesin dengan cara manual oleh manusia memiliki banyak keterbatasan. Karena mesin CNC dikendalikan oleh komputer atau mikrokontroler maka pergerakan pada sumbu $\mathrm{X}$ dan sumbu $\mathrm{Y}$ serta sistem $\mathrm{Z}$ dapat dikendalikan secara presisi mengikuti perintah [5].

Untuk melengkapi konstruksi mekanik mesin CNC, dibutuhkan sistem kontrol yang nantinya berfungsi sebagai otak mesin. Dimana seluruh parameter pemesinan nantiya akan di-setup dan dioperasikan melalui sistem kontrol tersebut. Sehingga mesin ini nantinya bisa berperilaku seperti mesin modern yang dapat beroperasi dalam tiga sumbu [6].

Para Peneliti telah memperoleh skematik sistem kontrol mesin CNC Laser, menghasilkan prototype mesin CNC Laser, dan nilai parameter dari data-data hasil uji kinerja mesin CNC Laser dengan mikro kontroller CNC 3 aksis berbasis Atmega328 Arduino nano.

Para Peneliti juga mendesain model mesin CNC laser cutting yang dapat memudahkan industri seni kreatif akrilik dalam pembuatan produk dengan waktu yang 
singkat dan dengan bentuk yang berbagai ragam variasi lainnya, sehingga dapat menciptakan daya saing dan produktivitas yang tinggi.

Sistem sumbu 3 aksis telah di kembangkan pada implementasi sistem control putaran motor untuk penggerak engkol pada mesin simulator gempa 3 axis. Mesin simulator gempa menggunakan 2 jenis motor listrik untuk menggerakkan mekanisme engkol penggerak shake table, motor DC untuk sumbu X,Y, dan motor AC untuk sumbu $\mathrm{Z}$, dikarenakan sumbu memiliki beban yang paling besar dari semua sumbu yang pada mekanismenya sumbu Y mendorong 3 buah kerangka meja, oleh karena itu menggunakan motor AC yang memiliki torsi motor yang besar[7]. Sistem control gerak telah di kembangkan untuk kepresisian proses pemotongan, dengan mengendalaikan putaran motor listrik [8].

Analisa pembebanan pada frame telah dilakukan dengan metode elemen hingga mengunakan sofware. Dasar dari metode elemen hingga adalah membagi benda kerja menjadi elemen-elemen kecil yang jumlahnya berhingga sehingga dapat menghitung reaksi akibat beban pada kondisi batas yang diberikan [9].

Penelitian ini bertujuan mendesain dan simulasi tegangan Mesin CNC Laser Cutting bersifat portable, alat ini menggunakan laser sebagai alat potong untuk mengerjakan benda kerja, dengan ukuran laser berdiameter $0,02 \mathrm{~mm}$, untuk memotong bahan akrilik dengan ketebalan $10 \mathrm{~mm}$.

\section{METODOLOGI PENELITIAN}

Proses desaian mesin cnc laser cutting ditunjukkan pada gambar 1 sebagai berikut. 


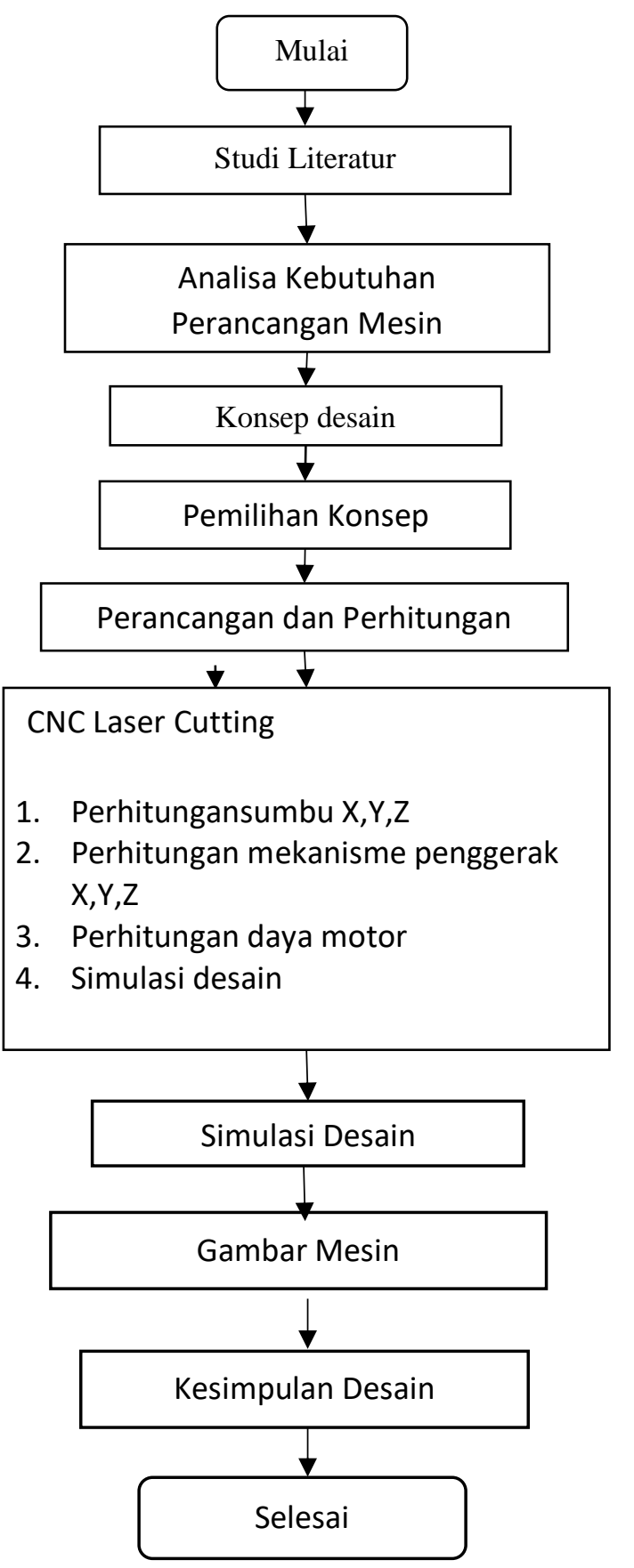

Gambar 1. Diagram alir perancangan mesin cnc laser cutting

1. Studi Literatur. 
Studi literatur meliputi : pencarian berupa jurnal dan skripsi-skripsi yang sudah pernah dibuat dan terkait dengan desain cnc laser cutting.

2. Analisa Kebutuhan.

Analisa kebutuhan : menyesuaikan kebutuhan dalam aspek teknik, aspek manufaktur, aspek perakitan, aspek perawatan, aspek ergonomi dan aspek lingkungan agar memudahkan pengguna alat tersebut.

3. Konsep Desain.

Melakukan proses konsep desain dengan memberikan gambaran perbandingan dari alat yang di bangun dengan suatu pengartian mesin cnc laser cutting.

4. Pemilihan konsep desain.

Melakukan proses pemilihan konsep desain dari beberapa konsep desain yang telah di sajikan, dengan mempertimbangkan segi keefektifitas sistem kerjannya.

5. Perancangan.

Menentukan modul laser, perhitungan motor, perhitungan sumbu, perhitungan mekanisme penggerak 3 sumbu (X,Y dan $\mathrm{Y})$.

6. Simulasi.

Melakukan simulasi desain dengan menggunakan software autodesk inventor academy 2019.

\section{HASIL DAN PEMBAHASAN}

\subsection{Analisa kebutuhan sistem}

Mekanisme perancangan mesin CNC Laser cutting ini menggunakan data primer dan data skunder, dimana data primer dilakukan dengan observasi dan data sekunder diperoleh dari buku, jurnal dan media internet sedangkan data primer dilakukan peninjau pada ukuran yang di butuhkan oleh konsumsi. Sehingga dapat memperbaiki kekurangan tersebut dan akhirnya dapat diperoleh rancangan dan akan dilakukan ke proses pembuatan mesin $C N C$ Laser cutting untuk pembuatan kerajinan berbahan akrilik

\subsection{Desain Mesin}

Konsep desain CNC Laser Cutting ini terdapat beberapa komponen yang digunakan seperti gambar 2 yang dibawah ini : 


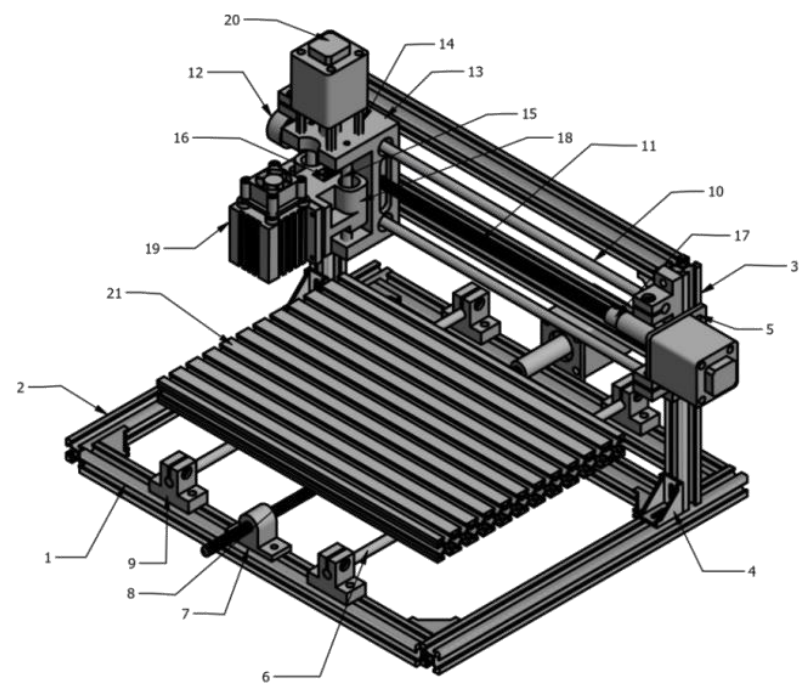

Gambar 2. Desain Mesin cnc laser cutting untuk produk berbahan akrilik.

Pada Gambar 2. terlihat bahwa mesin cnc laser cutting terdiri dari komponen : 1) Frame 1, 2) Frame 2, 3) Frame 3, 4) L shape joint, 5) Mounting motot stepper, 6) Poros pengarah sumbu Y, 7) Bracket bearing sumbu Y, 8)Lead screw sumbu Y, 9) Bracket poros pengarah, 10) Poros pengarah sumbu X, 11) Lead screw sumbu X, 12) Bracket bearing sumbu X, 13) Nut, 14) Spacer, 15) Poros pengarah sumbu Z, 16) Lead screw sumbu Z, 17) Fleksible couple, 18) Bracket modul laser, 19) Modul laser, 20) Motor stepper, 21) Meja kerja.

\subsection{Fungsi komponen}

1) Frame 1,2,3 berfungsi sebagai penompang komponen-komponen dan motor.

2) L shape joint berfugsi sebagai penyambung frame 1,2,3

3) Mounting motor stepper sebagai dudukan motor stepper.

4) Poros pengarah sumbu $Y$ berfungsi sebagai rail jalanya arah maju mundur work area.

5) Bracket bearing sumbu $Y$ berfungsi sebagai dudukan/bantalan ujung lead screw saat berputar.

6) Bracket poros pengarah berfungsi mendukung pengunci poros.

7) Poros pengarah sumbu $X$ berfungsi sebagai rail jalannya arah kekanan dan kekiri bracket modul laser.

8) Lead screw sumbu $\mathrm{X}$ berfungsi mendukung jalannya bracket sumbu $\mathrm{Z}$, sehingga bracket tersebut bisa berjalan kearah kanan dan kiri .

9) Bracket bearing sumbu X berfungsi sebagai dudukan/bantalan ujung lead screw saat berputar.

10) Nut berfungsi mendukung untuk kuncian bracket sumbu $X, Y$, dan $Z$ ke lead screw agar bias menjalankan ketiga bracket tersebut.

11) Spacer berfungsi sebagai penyangga motor stepper sumbu $Z$.

12) Poros pengarah sumbu $Z$ berfungsi sebagai rail jalanya arah keatas dan kebawah bracket modul laser. 
13) Lead screw sumbu $Z$ berfungsi mendukung jalannya arah bracket modul laser, sehingga laser dapat bergerak keatas dan kebawah

14) Fleksible couple berfungsi sebagai alat penyambung motor stepper ke lead screw.

15) Bracket modul laser berfungsi sebagai alat untuk mencekam modul laser.

16) Modul laser berfungsi untuk memotong atau menggores benda kerja.

17) Motor stepper berfungsi mendukung sebagai penggerak sumbu $X, Y, Z$.

18) Meja kerja sebagai dudukan/tempat benda kerja saat proses pemotongan bahan.

\subsection{Perhitungan Mesin}

a. CNC Laser Cutting ini memerlukan adanya perencanaan daya motor yang diperlukan agar sesuai dengan kebutuhan, dihitung dengan persamaan 1.

$$
n=60 \frac{P p s}{N s}
$$

Dimana $\mathrm{n}$ adalah kecepatan putar motor (rpm), Pps adalah kecepatan pulsa masuk(Pulsa/detik), Ns adalah banyaknya pulsa satu kali putar (Pulsa/rotasi).

Daya motor 3 Axis juga dapat dihitung dengan persamaan 2.

$$
v=\frac{\text { Panjang lead screw sumbu } X}{\text { Pitch lead screw }}
$$

Daya motor yang dibutuhkan untuk gerak maju dihitung dengan persamaan 3:

$$
P=T_{1} \cdot v
$$

Dimana $T_{1}$ adalah torsi lead screw gerak maju, $\mathrm{v}$ adalah putaran lead screw

Daya motor yang dibutuhkan untuk gerak mundur dihitung dengan persamaan 4 :

$$
P=T_{2} \cdot v
$$

Dimana $T_{2}$ adalah torsi lead screw gerak mundur, $\mathrm{v}$ adalah putaran lead screw

b. Perhitungan poros $\mathrm{X}, \mathrm{Y}$ dan $\mathrm{Z}$

Momen bengkok maksimum poros, dihitung dengan persamaan 5 .

$$
M b \max =\frac{W . L}{8}
$$

Dimana $M b$ max adalah momen bengkok maks (Nmm), $W$ adalah beban poros $(\mathrm{N})$, L adalah panjang poros $(\mathrm{mm})$

Tegangan pada poros, dihitung dengan persamaan 6 .

$$
f g=\frac{\sigma t \max }{8}
$$

Dimana fg adalah tegangan geser ijin $\left(\mathrm{N} / \mathrm{mm}^{2}\right)$ dan $\sigma$ t max adalah tegangan tarik maksimum $\left(\mathrm{N} / \mathrm{mm}^{2}\right)$

Diameter poros dihitung dengan persamaan 7 .

$$
d=\sqrt{\frac{4 \times w}{\pi \times \sigma_{t}}}
$$


Dimana d adalah diameter, 4 adalah satuan, w adalah beban bawaan $(\mathrm{N}), \sigma t$ adalah jenis poros alumunium $\left(\mathrm{N} / \mathrm{mm}^{2}\right)$,

c. Frame Mesin, dihitung dengan persamaan 8 .

$$
\sigma \text { izin }=M / E
$$

Dimana $\sigma$ izin adalah Tegangan Izin Suatu Bahan $(\mathrm{N} / \mathrm{mm})$, M adalah Momen Lentur $(\mathrm{N} / \mathrm{mm})$, E adalah Modulus elastisitas ( $\mathrm{mm})$

d. Momen Inersia, dihitung dengan persamaan 9 .

$$
I=I_{X^{\prime}}=\frac{1}{12} b h^{3}-\frac{1}{12} b^{\prime} h^{\prime 3}
$$

e. Tegangan Permukaan dihitung dengan persamaan 10 .

$$
\sigma=\frac{M \cdot C}{I}
$$

Dimana $\mathrm{M}$ adalah Momen, $\mathrm{C}$ adalahTitik tengah y , I adalah Momen inersia pada frame

f. Tegangan Von mises, dihitung dengan persamaan 11 .

$$
\text { safety factor }=\frac{\text { Yield Point Stress }}{\text { Working atau design stress }}
$$

Pada perhitungan mesin menghasilkan nilai seperti pada tabel 1, 2, 3 dan 4 .

Tabel.1 hasil perhitungan daya motor mesin cnc laser cutting

\begin{tabular}{ll}
\hline Perhitungan & Hasil \\
\hline Daya motor gerak maju sumbu X & $6,84 \mathrm{Watt}$ \\
\hline Daya motor gerak mundur sumbu X & $4,58 \mathrm{Watt}$ \\
\hline Daya motor gerak maju pada sumbu Y & $9,97 \mathrm{Watt}$ \\
\hline Daya motor gerak mundur pada sumbu Y & $4,58 \mathrm{Watt}$ \\
\hline Daya motor gerak maju pada sumbu Z & $4,664 \mathrm{Watt}$ \\
\hline Daya motor gerak mundur pada sumbu Z & $3,12 \mathrm{Watt}$ \\
\hline
\end{tabular}

Tabel. 2 hasil perhitungan poros sumbu $X$ cnc laser cutting

\begin{tabular}{ll}
\hline Perhitungan & Hasil \\
\hline Tegangan geser ijin poros & $17 \mathrm{~N} / \mathrm{mm}^{2}$ \\
\hline Tegangan bengkok & $176 \mathrm{~N} / \mathrm{mm}^{2}$ \\
\hline Momen bengkok & $778,68 \mathrm{Nmm}$ \\
\hline Diameter poros & $0,31 \mathrm{~mm}$ \\
\hline
\end{tabular}

Tabel 3 hasil perhitungan poros sumbu Y cnc laser cutting

\begin{tabular}{ll}
\hline Perhitungan & Hasil \\
\hline Tegangan geser ijin poros & $17 \mathrm{~N} / \mathrm{mm}^{2}$ \\
\hline Tegangan bengkok & $176 \mathrm{~N} / \mathrm{mm}^{2}$ \\
\hline Momen bengkok & $292000 \mathrm{Nmm}$ \\
\hline Diameter poros & $8 \mathrm{~mm}$ \\
\hline
\end{tabular}


Tabel.4 hasil perhitungan poros sumbu $\mathrm{Z}$ cnc laser cutting

\begin{tabular}{ll}
\hline Perhitungan & Hasil \\
\hline Tegangan geser ijin poros & $17 \mathrm{~N} / \mathrm{mm}^{2}$ \\
\hline Tegangan bengkok & $176 \mathrm{~N} / \mathrm{mm}^{2}$ \\
\hline Momen bengkok & $939000 \mathrm{Nmm}$ \\
\hline Diameter poros & $8 \mathrm{~mm}$ \\
\hline
\end{tabular}

\subsection{Analisa Tegangan pada Frame}

3.1 Besar tegangan von mises pada rangka/frame ditunjukkan pada gambar 3

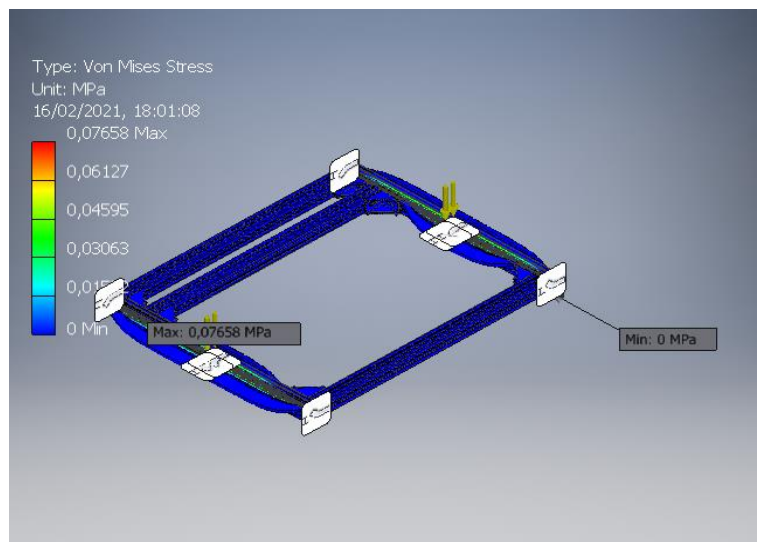

Gambar. 3. Analisa Von mises stress pada frame cnc laser cutting

Pada gamabar 3 menunjukan distribusi tegangan ke seluruh bagian geometri mesin cnc laser cutting mempunyai nilai von mesis stress sebesar 0,07658 Mpa dan nilai von mises stress minimal $0 \mathrm{Mpa}$.

3.2 Nilai Displacement pada mesin cnc laser cutting pada gambar 4

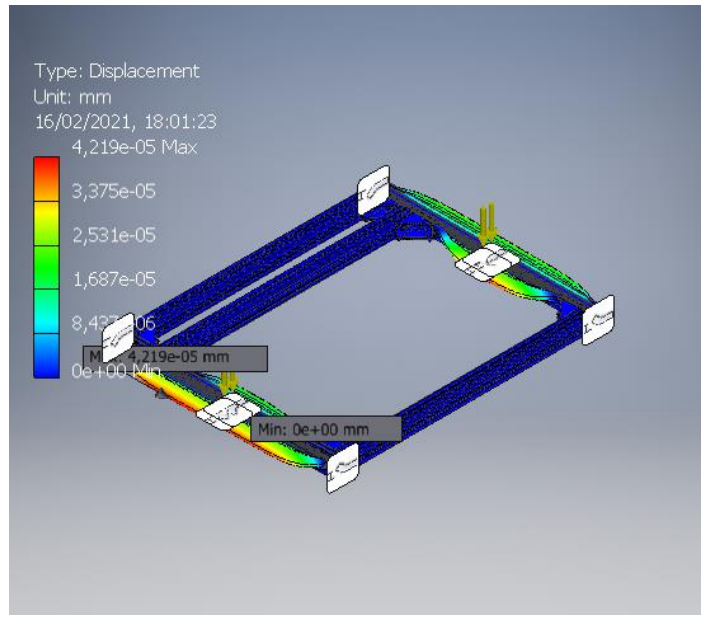

Gambar .4. Displacement pada rangka mesin cnc laser cutting 
Gambar menunjukan distribusi tegangan ke seluruh bagian geometri rangka mesin cnc laser cutting mempunyai nilai Displacement maximal sebesar 4,219e-05 mm dan nilai Displacement minimal sebesar $0 \mathrm{~mm}$..

Berdasarkan hasil penelitian terhadap desain mesin laser cutting mempunyai daya 35 Watt, daya modul laser 5,5 Watt dan torsi yang terjadi $22,58 \mathrm{Kg} / \mathrm{mm}$ yang mempunyai tegangan geser izin sebesar $17 \mathrm{Kg} / \mathrm{mm}^{2}$ mesin ini menggunakan poros berdiameter $8 \mathrm{~mm}$ yang sesuai dengan bantalan 6006 yang digunakan, dengan dimensi mesin 450x400x300, dimensi work area 300x200x35, kecepatan potong $22 \mathrm{~s}$ di setiap panjang akrilik $200 \mathrm{~mm}$ dan peneliti menggunakan metode elemen hingga dalam merancang desain dan mensimulasikan mesin cnc laser cutting

\section{KESIMPULAN}

Hasil penelitian ini adalah sebagai berikut Telah dihasilkan desain mesin cnc laser cutting dengan dimensi mesin 450x400x300, dimensi work area 300x200x35, kecepatan potong $22 \mathrm{~s}$ di setiap panjang akrilik $200 \mathrm{~mm}$, daya penggerak 35 Watt dan daya modul laser 5,5 Watt. Hasil simulasi von mises stress menggunakan metode elemen hingga. Komponen yang dianalisa dalam penelitian ini adalah frame mesin mendapatkan hasil simulasi nilai vonmises-stress frame adalah 0,07658 Mpa.

\section{DAFTAR PUSTAKA}

[1] F. J. Daywin, D. W. Utama, W. Kosasih, and K. William, "Perancangan Mesin 3d Printer Dengan Metode Reverse Engineering (Studi Kasus di Laboratorium Mekatronika dan Robotics Universitas Tarumanagara) Frans Jusuf Daywin, Didi Widya Utama, Wilson Kosasih, Kevin William," vol. 7, no. 2, pp. 79-89, 2019.

[2] A. R. Widiyanto, Alfi rindi, Alfi Iklima, 2018, Prototype Pembuatan Cnc Dengan Pemanfaatan Pemanfaatan Motor Stepper Berbasis Arduino Uno, thesis, Universitas Teknologi Yogyakarta.

[3] B. Suprianto, "Rancang Bangun Mesin Cnc Milling 3- Axis Untuk," vol. 3, no. 1, pp. 4047, 2019.

[4] G. Kahl, "L aser- c apture m icrodissection (LCM) ," Dict. Genomics, Transcr. Proteomics, vol. 15, no. 01, pp. 1-1, 2015, doi: 10.1002/9783527678679.dg06699.

[5] S. Suroso, A. Lukmana, and N. T. Sanyoto, "Pengembangan Mechanic Cutting Dengan Tiga Derajat Kebebasan Berbasis Ballscrew," MATRIK (Jurnal Manaj. dan Tek., vol. 17, no. 1, p. 73, 2017, doi: 10.30587/matrik.v17i1.165.

[6] H. Fauzi, 2018, Rancang Bangun Sistem Kontrol Mesin Laser Engraving, President University Lembar Pernyataan Keaslian," no. May, 2018.

[7] A. Ghany, M. Kabib, Qomaruddin, Taufiq Hidayat, 2020, Desain Dan Implementasi Sistem Kontrol Putaran Motor Pada Gerak Simulator Gempa 3 Axis, jurnal Cracnkshaft, vol. 3, no. 1, pp. 25-34, 2020.

[8] P. Kushartanto, M. Kabib, R. Winarso, 2019, Sistem Kontrol Gerak Dan Perhitungan Produk Pada Mesin Pres Dan Pemotong Kantong Plastik, Jurnal Crankshaft, Volume 2 No. 1, pp 57-66.

[9] S. Kuntoro, M. Kabib, 2018, Analisis Kekuatan Dies Frame Link Pada Mesin Roll Pipa 2 In Penggerak Hidrolik Dengan Metode Elemen Hingga, Jurnal Simetris, Volume 9, Nomor 2, pp. 941 - 946 